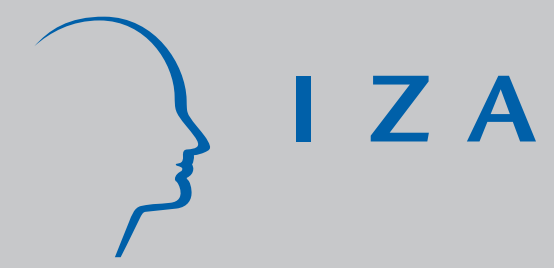

IZA DP No. 1052

Consumption Smoothing and the Structure of Labor and Credit Markets

Giuseppe Bertola

Winfried Koeniger

March 2004 


\title{
Consumption Smoothing and the Structure of Labor and Credit Markets
}

\author{
Giuseppe Bertola \\ Università di Torino, \\ EUI and CEPR
}

\section{Winfried Koeniger}

IZA Bonn

Discussion Paper No. 1052

March 2004

\author{
IZA \\ P.O. Box 7240 \\ 53072 Bonn \\ Germany
}

Phone: +49-228-3894-0

Fax: +49-228-3894-180

Email: iza@iza.org

Any opinions expressed here are those of the author(s) and not those of the institute. Research disseminated by IZA may include views on policy, but the institute itself takes no institutional policy positions.

The Institute for the Study of Labor (IZA) in Bonn is a local and virtual international research center and a place of communication between science, politics and business. IZA is an independent nonprofit company supported by Deutsche Post World Net. The center is associated with the University of Bonn and offers a stimulating research environment through its research networks, research support, and visitors and doctoral programs. IZA engages in (i) original and internationally competitive research in all fields of labor economics, (ii) development of policy concepts, and (iii) dissemination of research results and concepts to the interested public.

IZA Discussion Papers often represent preliminary work and are circulated to encourage discussion. Citation of such a paper should account for its provisional character. A revised version may be available on the IZA website (www.iza.org) or directly from the author. 
IZA Discussion Paper No. 1052

March 2004

\section{ABSTRACT \\ Consumption Smoothing and the Structure of Labor and Credit Markets*}

Smoother labor incomes alleviate credit constraints by reducing workers' desire to borrow, and prospects of upward income mobility have smaller beneficial effects for currently poor workers when borrowing constraints are binding. These simple theoretical insights are consistent with the empirically more pronounced tendency of poor would-borrowers to favor government redistribution in countries where consumer credit is relatively scarce. They may also explain observed institutional patterns across countries and markets: policies that reduce the dispersion and volatility of labor income appear to be more prevalent in countries where inefficient legal systems restrict borrowing opportunities. Our theoretical perspective and empirical results offer more general insights as to ways in which historically determined features and politico-economic interactions may jointly shape institutional aspects of different markets, and as to appropriate design of reform processes.

JEL Classification: E21, E24, E61

Keywords: $\quad$ labor market institutions, consumer credit, redistribution, borrowing constraints

Corresponding author:

Winfried Koeniger

IZA Bonn

P.O. Box 7240

53072 Bonn

Germany

Email: koeniger@iza.org

\footnotetext{
* This work is part of the Finance and Consumption in the EU Chair research program, sponsored by Findomestic Banca and CETELEM at the European University Institute. For helpful comments on previous drafts we are grateful to Torben Andersen, Daniele Checchi, Gianluca Femminis, Olmo Silva, Etienne Wasmer, and workshop participants at Università del Piemonte Orientale, IZA Bonn, IIES Stockholm, CEP London, German Economic Association, and Università Cattolica Milano.
} 


\section{Introduction}

Since the structures of different markets interact in determining the behavior and welfare of agents operating in all of them, financial market imperfections can rationalize institutional interference with laissez faire labor market outcomes. Varian (1980) and other references in Agell (2002) show that redistributive labor income taxation has beneficial effects in the absence of insurance markets. Unemployment insurance (Acemoglu and Shimer, 1999) or employment protection (Bertola, 2004) can also address efficiency and insurance issues when financial markets are realistically incomplete. The operation of markets and the desirability of policy interventions are in turn determined jointly by an economy's structural and political features: Rodrik, Subramanian, and Trebbi (2002) review and extend recent work on the theoretical and empirical relationship between policies, outcomes, and "deep" institutional quality features. In general, government interventions cannot provide costlessly the same insurance that markets fail to provide. Hence, policy interventions typically need to trade-off consumption stability and production efficiency. The shape of the relevant trade-off depends on the economy's structure as well as on details of policy implementation. It is likely to be sharply different across different countries and periods, and can potentially explain the equally sharp differences observed as regards the extent and character of institutional interference with laissez faire market outcomes.

In this paper, we focus on the behavior and welfare of workers-consumers whose labor income fluctuates over time, and study how their desire and ability to borrow against future labor income depend on institutional features of both labor and credit markets. This admittedly narrow perspective is empirically useful because indicators of consumer credit market development are more readily and more easily interpreted than information about other aspects of individuals' access to financial instruments, and labor market outcomes and institutions data are also available and interestingly heterogeneous across countries. Chatterjee et al. (2002) calibrate on U.S. data a general equilibrium model where consumers face labor income risk, and default opportunities limit their access to credit at the same time as they make it possible for them to obtain partial insurance. In the United States a largely unregulated labor market is indeed an important source of risk for households, and the consumer credit industry is very well developed. In other countries, however, labor market risk is more pervasively controlled by various institutional features, and credit is more scarce.

The cross-country relationship between consumer credit and labor market indicators is sufficiently clear to motivate our theoretical and empirical work. Figure 1 plots all available country observations for an index of labor market regulation, the OECD employment protection indicator (EPL), and an index of consumer borrowing opportunities, the loan-to-value collateral 


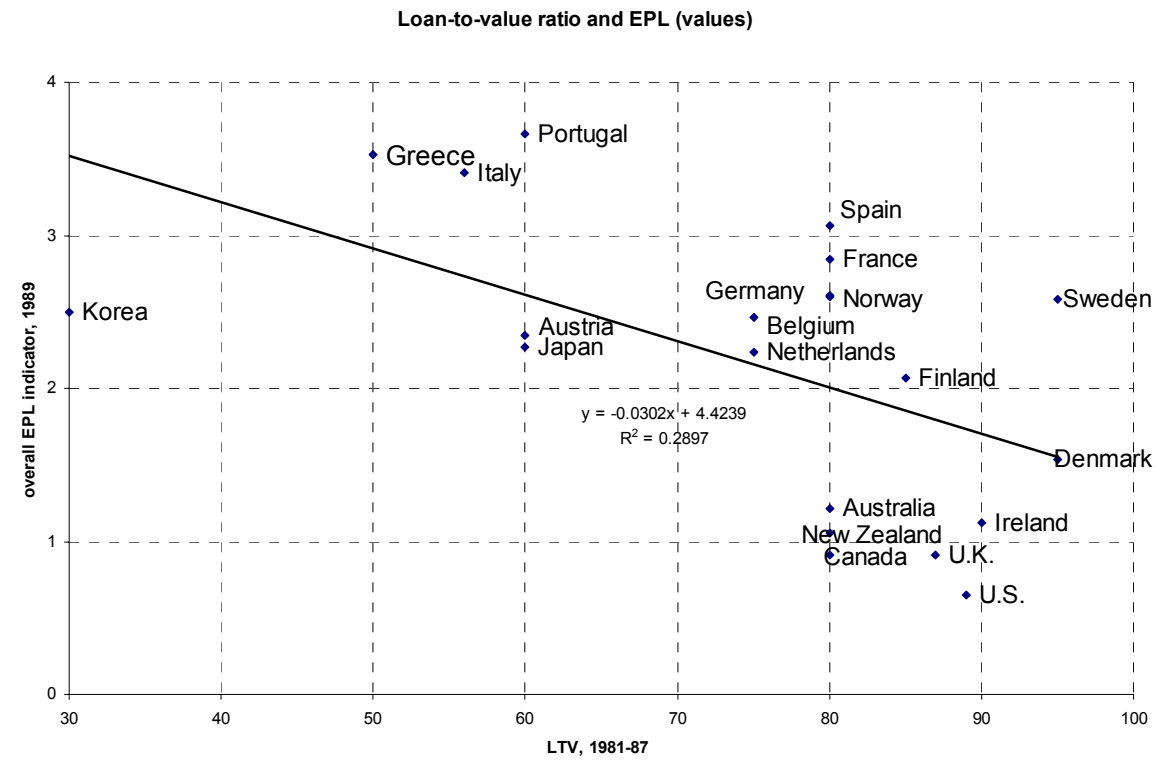

Figure 1: Employment protection and loan-to-value ratio in OECD countries; Source: see the Data Appendix.

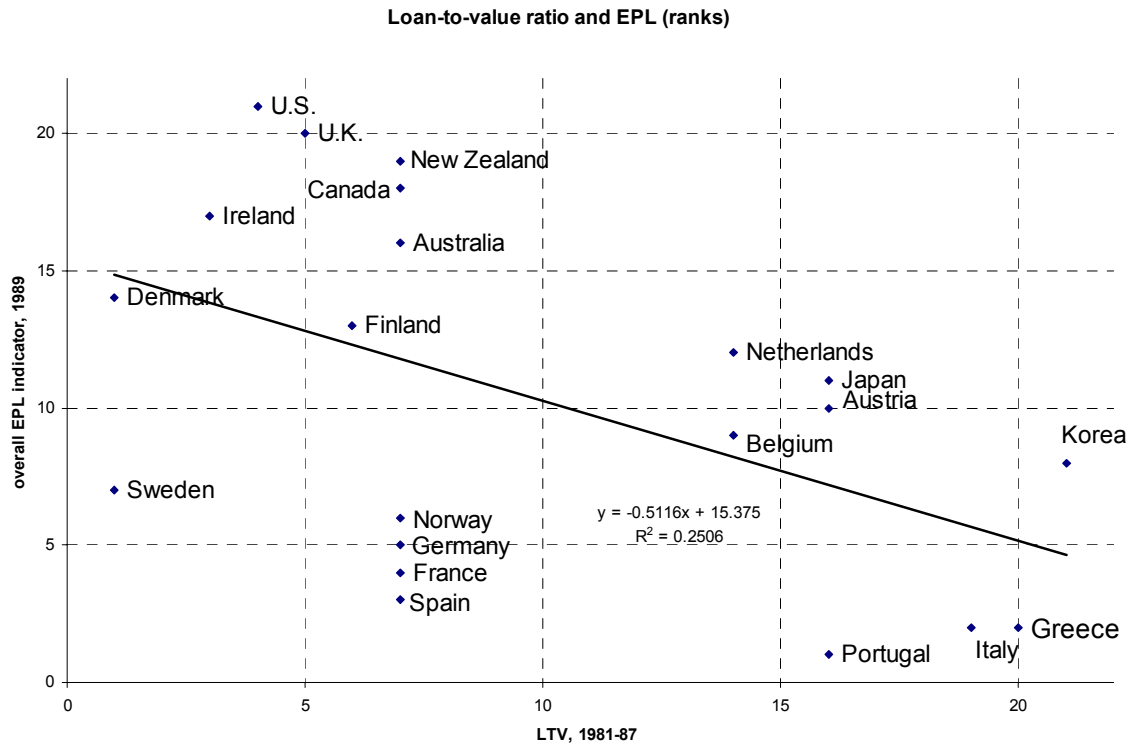

Figure 2: Rankings across countries of the same variables as in the previous figure. 
requirements (LTV) compiled by Jappelli and Pagano (1994). Since there is little reason to expect their relationship to be linear, we also plot in Figure 2 the ranking across countries of the same variables.

Many interpretations of this type of evidence are possible. For example, the empirical association between employment protection and constrained borrowing opportunities motivates Fogli (2000) to study family-level interactions: young people live longer with their parents in countries where stringent EPL implies slim job-finding chances and credit is scarce than in countries where labor markets are flexible and borrowing is easy. And Pagano and Volpin (2002) show that EPL's role in deterring takeover bids is especially important in countries where protection of shareholder's rights is weak. Interpreting cross-country evidence in light of such structural interactions between agents and markets requires identifying assumptions as to exogenous sources of institutional and outcome variation. Following La Porta et al. (1998), Botero et al. (2003), and other recent contributions, it is possible to view judicial and legal systems as an exogenous source of institutional variability across countries. We argue that the significant cross-country correlation of borrowing constraints with employment protection legislation and other institutions may reflect the attractiveness of stable labor incomes in countries where judicial problems reduce the supply of consumer credit.

Section 2 uses a simple model to show that the negative welfare implications of credit constraints are more pronounced when labor income profiles make borrowing more desirable. Labor income stability reduces desired borrowing by individuals who expect their income to increase, and may make it easier for them to obtain credit because a more favorable worst-case labor income enhances loan-repayment ability. Hence, income-compressing policies make it possible to smooth consumption intertemporally as well as across different states of the world, and their welfare benefits are more pronounced for the currently poor than a simpler insurancebased perspective would make them. The intensity of this effect depends intuitively on the volatility of income fluctuations: redistribution is less appealing for currently poor individuals who can look forward to future reversals of fortune, as shown by Benabou and Ok (2001), but credit constraints weaken the welfare impact of future income expectations. And, from any $e x$ ante policy-choice perspective, deadweight losses deriving from income-smoothing policies are less of an obstacle to their adoption when underdeveloped credit markets make it difficult for workers to shelter their consumption from labor income fluctuations.

Section 3 seeks empirical support for these insights. First, we test whether would-be borrowers support government redistribution more strongly in countries where credit access is more limited. International survey data, analyzed from an empirical perspective similar to that of Alesina and La Ferrara (2001), are consistent with the theoretical relationship between coun- 
tries' judicial and credit structure and their citizens' heterogeneous inclinations to approve redistributive policies. Then, we inspect cross-country indicators to see whether economies which find it more difficult to supply credit efficiently also implement policies that foster stable labor incomes and compressed earnings. Lack of empirical information prevents formal tests, but an exogenous source of financial market efficiency variation is consistent with a large number of correlations, similar to those illustrated in Figures 1 and 2, between indicators of industrialized countries' credit and labor market outcomes and institutions.

Section 4 concludes discussing more general implications of our theoretical and empirical perspective and noting in particular that the desirability and political feasibility of reforms in each of an economy's labor and financial market depend on the other's structure.

\section{$2 \quad$ A model}

The simple model we propose and solve is meant to represent qualitative insights of broader generality. We consider two periods in the life of consumers who wish to maximize

$$
U=u\left(c_{1}\right)+\beta E\left[u\left(c_{2}\right)\right]
$$

where $U$ and $u(\cdot)$ respectively denote lifetime and instantaneous utility; $c_{t}$ denotes consumption in period $t ; \beta$ is the discount factor, and $E[\cdot]$ is a conditional expectation formed on the basis of possibly constrained saving behavior and of the individual's labor income process. The latter is random, due to labor-demand or individual-specific shocks. In each of the two periods, labor income takes one of two values, $w_{b}$ and $w_{g}$. If the low value $w_{b}<w_{g}$ is realized in the first period, in the second period labor income still equals $w_{b}$ with probability $1-p$ and increases to $w_{g}$ with probability $p$. Symmetrically, a high first-period labor income persists with probability $1-p$ and falls to $w_{b}$ with probability $p$. In the individual's budget constraint, let $r$ be the interest rate on any borrowing or lending. It may depend on the economy's capital intensity, or on the lenders' cost of funds and of administering the contract, and might in general differ from the interest rate earned on assets. For our purposes, however, it will suffice to treat it as a constant parameter of the consumer's problem. ${ }^{1}$

Since $w_{b}<w_{g}$ and $p>0$, individuals who earn $w_{b}$ in the first period expect their income

\footnotetext{
${ }^{1}$ A longer time horizon would make it necessary to model wealth dynamics. Like more general wage distributions, this would introduce realistic heterogeneity in the economy but the model would have to be studied numerically, or for specific functional forms. It would be easy to allow for expected labor income growth, with implications similar to those of heavier discounting of future utility, and model explicitly life-cycle consumption and savings patterns.
} 
to increase, and if

$$
u^{\prime}\left(w_{b}\right)>\beta(1+r)\left[p u^{\prime}\left(w_{g}\right)+(1-p) u^{\prime}\left(w_{b}\right)\right]
$$

they would like to borrow in order to smooth their intertemporal consumption profile. As long as $p<1$, however, there is uncertainty around the expectation of higher income, and this affects credit supply conditions. In the model and in the real world, borrowing is constrained by repayment limits. In general, and in reality, lax ex post enforcement of repayment obligations restricts ex ante borrowing opportunities. In our simple model we suppose that enforcing loan repayment is impossible if this would reduce second-period consumption below a strictly positive lower bound, and that the borrower's labor income cannot be verified. Since a borrower's realized income may remain flat at $w_{b}$, we assume:

Assumption 1: It is impossible to borrow more than $\left(\kappa+\xi w_{b}\right) /(1+r)$, where $\kappa<(1-\xi) w_{b}$.

When the borrower's labor income remains low, this borrowing limit prevents secondperiod consumption from falling below the positive upper bound $(1-\xi) w_{b}-\kappa>0$ upon repayment. ${ }^{2}$ Inability to verify whether realized labor income is higher prevents lenders from recovering larger payments. Hence, larger loans are not granted, all loans are repaid in full, and the interest rate $r$ need not reflect repayment risk. It would be possible to model less extreme forms of imperfect enforcements at the cost of complicating the following derivations, where the sharpness of Assumption 1 will conveniently allow $\kappa$ to index borrowing limits due to imperfect enforceability of repayment obligations. Borrowing limits are affected by the lower bound $w_{b}$ of future labor income if $\xi>0$. This is realistic in that loans are more easily obtained by individuals whose jobs are secure (in Italy, and in other countries where dependent employment is a very stable source of income, loans can be explicitly collateralized by a portion of the borrower's wages, subsequently paid directly to the creditor). Through this channel credit supply depends not only on the structural features of the credit market studied by Jappelli and Pagano (1994) and others, but also on aspects of the same labor-income process that also determines demand for credit.

\subsection{Costs and benefits of redistribution}

We are interested in welfare interactions between credit constraints and redistributive labor market policies, such as unemployment or low-wage subsidies funded by payroll taxes. Formally, we consider a tax-and-subsidy scheme that decreases by $\tau \geq 0$ the take-home pay of

\footnotetext{
${ }^{2}$ In the limit case case $\kappa=(1-\xi) w_{b}$ there is no exogenous restriction on borrowing behavior if marginal utility tends to infinity at zero, ruling out optimality of zero consumption with positive probability (Carroll, 1997).
} 
individuals earning $w_{g}$ and increases by $\lambda \tau$ that of individuals earning $w_{b}$. Denoting with $\omega_{i}$ the laissez faire labor income of group $i$, when a policy of this type is implemented high-wage workers earn $w_{g}=\omega_{g}-\tau$ and low-wage workers earn $w_{b}=\omega_{b}+\tau \lambda$. The parameter $\tau$ indexes the intensity of redistribution or, more generally, of institutional interference with laissez faire labor income inequality. The parameter $\lambda$ simply indexes the benefits of redistribution for low-income workers as far as individual welfare effects are concerned, and can be given an interpretation in terms of deadweight losses when the policy is assessed at the aggregate level (see Section 2.2 below).

We will study the welfare implications of this type of policy under the assumption that $u^{\prime}\left(w_{g}\right)<\beta(1+r)\left[p u^{\prime}\left(w_{b}\right)+(1-p) u^{\prime}\left(w_{g}\right)\right]$. This makes it optimal for initially lucky workers to carry assets with liquidation value $a>0$ to the second period of their life, and achieve welfare

$$
U_{g} \equiv u\left(w_{g}-\frac{a}{1+r}\right)+\beta\left[p u\left(w_{b}+a\right)+(1-p) u\left(w_{g}+a\right)\right]
$$

As $a$ is chosen so as to satisfy the unconstrained Euler equation, a policy perturbation has no first-order welfare effects through saving behavior. Hence,

$$
\frac{d U_{g}}{d \tau}=-u^{\prime}\left(w_{g}-\frac{a}{1+r}\right)-\beta(1-p) u^{\prime}\left(w_{g}+a\right)+\beta p \lambda u^{\prime}\left(w_{b}+a\right) .
$$

This expression can be positive, as long as $\lambda$ is not so small as to make redistribution ineffective, if utility is very concave and $p$ is large enough to make insurance an important concern for this group of individuals.

For workers who start at low labor income in the first period, the constraint imposed by Assumption 1 is binding if borrowing more than $b=-\left(\kappa+\xi w_{b}\right)$ would be necessary in order to satisfy the Euler equation. In this case the shadow price of the constraint is positive:

$$
\mu\left(w_{b}, w_{g}, \kappa\right) \equiv u^{\prime}\left(w_{b}+\frac{\kappa+\xi w_{b}}{1+r}\right)-\beta(1+r)\left[p u^{\prime}\left(w_{g}-\kappa-\xi w_{b}\right)+(1-p) u^{\prime}\left(w_{b}-\kappa-\xi w_{b}\right)\right]>0 .
$$

Slackness of the Euler condition implies that exchanging one unit of future consumption for $(1+r)^{-1}$ units of current consumption improves a credit-constrained individual's welfare. If the financial market cannot provide better borrowing opportunities, it is interesting to explore how the welfare of initially low-income individuals,

$$
U_{b}=u\left(w_{b}+\frac{\kappa+\xi w_{b}}{1+r}\right)+\beta\left[p u\left(w_{g}-\kappa-\xi w_{b}\right)+(1-p) u\left(w_{b}-\kappa-\xi w_{b}\right)\right],
$$

may benefit from a relaxation of borrowing constraints though an improvement of the worst- 
case labor income. Like its counterpart in (4) for positive-assets individuals,

$$
\begin{aligned}
\frac{d U_{b}}{d \tau}= & u^{\prime}\left(w_{b}+\frac{\kappa+\xi w_{b}}{1+r}\right) \lambda+\mu\left(w_{b}, w_{g}, \kappa\right) \frac{\xi \lambda}{1+r} \\
& +\beta\left((1-p)\left[\lambda u^{\prime}\left(w_{b}-\left(\kappa+\xi w_{b}\right)\right)\right]-p\left[u^{\prime}\left(w_{g}-\left(\kappa+\xi w_{b}\right)\right]\right)\right.
\end{aligned}
$$

can but need not be positive, depending on the strength of insurance concerns and on the effectiveness of redistribution in addressing them. However, the positive shadow price $\mu(\cdot)$ quite intuitively tends to increase the welfare benefits of redistribution for individuals who would like to borrow against a higher expected future income, but are prevented from doing so by borrowing constraints motivated by solvency constraints. The welfare effect of the tightness of borrowing constraints, as indexed by $\kappa$ in Assumption 1 , is $d U_{b} / d \kappa=\mu\left(w_{b}, w_{g}, \kappa\right) /(1+r)$. Its interaction with redistribution is

$$
\begin{aligned}
\frac{\partial^{2} U_{b}}{\partial \kappa \partial \tau}= & \frac{1}{1+r} \frac{\partial \mu\left(\omega_{b}+\lambda \tau, \omega_{g}-\tau, \kappa\right)}{\partial \tau} \\
= & \frac{\lambda}{1+r} u^{\prime \prime}\left(w_{b}+\frac{\kappa+\xi w_{b}}{1+r}\right)\left(1+\frac{\xi}{1+r}\right) \\
& +\beta\left\{(\xi \lambda+1) p u^{\prime \prime}\left(w_{g}-\left(\kappa+\xi w_{b}\right)\right)+(\xi-1) \lambda(1-p) u^{\prime \prime}\left(w_{b}-\left(\kappa+\xi w_{b}\right)\right)\right\} .
\end{aligned}
$$

This mixed derivative is certainly negative if

$$
\frac{\lambda}{1+r} u^{\prime \prime}\left(w_{b}+\frac{\kappa+\xi w_{b}}{1+r}\right)-\beta \lambda(1-p) u^{\prime \prime}\left(w_{b}-\left(\kappa+\xi w_{b}\right)\right)<0,
$$

which is implied by the condition (2) for borrowing to be desirable if ${ }^{3}$

$$
\frac{u^{\prime \prime}\left(w_{b}-\left(\kappa+\xi w_{b}\right)\right)}{u^{\prime \prime}\left(w_{b}+\frac{\kappa+\xi w_{b}}{1+r}\right)}<1+\frac{p}{1-p} \frac{u^{\prime}\left(w_{g}\right)}{u^{\prime}\left(w_{b}\right)} .
$$

The right-hand side of (10) is larger than unity, and its left-hand side is certainly smaller than or equal to one if $u^{\prime \prime \prime}(\cdot) \leq 0$. Thus, we have

Result 1: If $u^{\prime \prime \prime}(\cdot) \leq 0$ or the more general sufficient condition (10) holds, then redistribution is more beneficial for borrowers when credit is tighter, as indexed by a smaller $\kappa$ in Assumption 1.

\footnotetext{
${ }^{3}$ The sufficient condition $(9)$ can be written $(1-p) u^{\prime \prime}\left(w_{b}-\left(\kappa+\xi w_{b}\right)\right) / u^{\prime \prime}\left(w_{b}+\frac{\kappa+\xi w_{b}}{1+r}\right)<\frac{1}{\beta(1+r)}$ and $(2)$ can be written $1-p \frac{u^{\prime}\left(w_{b}\right)-u^{\prime}\left(w_{g}\right)}{u^{\prime}\left(w_{b}\right)}<\frac{1}{\beta(1+r)}$. The latter inequality implies the former if (10) holds.
} 
Intuitively, when credit markets afford less consumption smoothing then redistribution plays a more beneficial role in appropriately aligning borrowers' marginal utilities over time and across labor-income realizations. It is also not difficult to see that more efficient credit markets can make redistribuition more attractive when a strongly positive $u^{\prime \prime \prime}(\cdot)$ introduces precautionary motives for individual saving and borrowing choices. Less dispersed secondperiod income induces more borrowing by a prudent consumer, and can increase the welfare impact $\mu(\cdot)$ of borrowing constraints if marginal utility is strongly convex. On the other side of the same coin, allowing larger debt makes insurance more desirable if repayment upon realization of low labor income brings consumption to a steeply decreasing portion of the marginal utility function.

Since upward income mobility makes borrowing more desirable for low-income individuals, it is also intuitive to find that a larger $p$ on the right-hand side of Result 1's sufficient condition (10) makes it easier for it to hold. We proceed to analyze the welfare implications of that parameter in more detail.

\subsubsection{Labor-income persistence and credit constraints}

We have shown that redistribution tends to be less attractive if credit markets are relatively more developed. A larger $p$, for any given labor income differential $w_{g}-w_{b}$, implies a steeper slope of expected income profiles and stronger desire to borrow in our simple model. Since lifetime welfare can also be equalized by a high likelihood $p$ of transitions across the model's labor-income realizations, it is interesting to explore in more detail the role of that parameter.

The effect of a higher $p$ on the welfare of the initially unlucky and liquidity constrained individuals, in equation (6) above, is

$$
\frac{\partial U_{b}}{\partial p}=\beta\left[u\left(w_{g}-\kappa-\xi w_{b}\right)-u\left(w_{b}-\kappa-\xi w_{b}\right)\right]>0 .
$$

The derivative is clearly positive, since a larger $p$ makes a high income more likely in the second period. Symmetrically, the effect of a higher $p$ on the welfare (3) of the individuals who have high wages and save initially is negative,

$$
\frac{\partial U_{g}}{\partial p}=\beta\left[u\left(w_{b}+a\right)-u\left(w_{g}+a\right)\right]<0,
$$

where the envelope theorem allows us to neglect the effect of $p$ on $a$. The effect is more negative when lucky agents do not bring large assets to the future, and less negative if wage inequality is less pronounced (possibly as a result of tax-and-subsidy policy).

Recalling that redistribution affects wages according to $d w_{g}=-d \tau, d w_{b}=\lambda d \tau$, our simple setting offers an equally simple representation of the prospect-of-upward-mobility (POUM) 
effect analyzed by Benabou and Ok (2001):

$$
\frac{\partial^{2} U_{b}}{\partial \tau \partial p}=-\beta\left[u^{\prime}\left(w_{g}-\kappa-\xi w_{b}\right)(1+\xi \lambda)+u^{\prime}\left(w_{b}-\kappa-\xi w_{b}\right) \lambda(1-\xi)\right]<0 .
$$

Income mobility leads currently poor agents to like redistribution less, and may even lead them to oppose it if $\lambda$ is small and $p$ is large. However, our simple model delivers an unambiguous sign prediction for the relationship between the index of (upward) income mobility $p$ of initially low-income individuals, and the interaction between redistribution and liquidity constraints on which we focus:

$$
\frac{\partial^{3} U_{b}}{\partial \tau \partial p \partial \kappa}=\beta\left[u^{\prime \prime}\left(w_{g}-\kappa-\xi w_{b}\right)(1+\xi \lambda)+u^{\prime \prime}\left(w_{b}-\kappa-\xi w_{b}\right) \lambda(1-\xi)\right]<0,
$$

and this establishes

Result 2: The benefits of redistribution for individuals who are currently poor are smaller when these individuals can look forward to more strongly increasing expected income ( $p$ is large) and credit is less restricted ( $\kappa$ is large).

Intuitively, less efficient credit markets weaken the welfare impact of income mobility because they prevent low income agents to anticipate more of their higher future labor income. Hence, the POUM effect is less pronounced when borrowing is more constrained. The welfare effect of higher future income (a steeper expected labor income profile) is larger when consumption can be smoothed by borrowing. The effect becomes less pronounced if $w_{g}-w_{b}$ is smaller, as might be implied by a more incisive tax-and-subsidy policy of the type we consider above.

\subsection{Policy choices}

In reality, complex political processes aggregate conflicting individual preferences. Qualitatively, the interaction characterized above between redistribution and liquidity constraints should lead any political process that assigns positive weight to borrowers' preferences, to result in more redistribution when credit supply is more restricted. To provide a simple formal illustration we consider an economy where equal, large numbers of individuals initially earn each of the two wage levels introduced above, and transitions between first and second period wage levels are idiosyncratic. Since half of the economy's individuals earn each of the two possible wages in each of the periods, $\lambda<1$ when $\tau \geq 0$ represents the negative efficiency effects of redistribution policies. We continue to suppose that the labor-income effects of the policy 
we model are the same in both periods, and the individual transition probabilities across the two labor incomes are symmetric; more general specifications of either aspect would not affect our qualitative results. ${ }^{4}$

Also for simplicity, we analyze the appeal of redistribution from the "constitutional" point of view of a policymaker whose ex ante objective function weighs the two groups equally: qualitatively, the results would be similar for any specification of policy choices that assigns positive weight to the poor would-be borrowers that benefit more strongly from redistribution when credit is more constrained. The optimal policy from this point of view satisfies the first order condition

$$
\frac{\partial\left(U_{b}+U_{g}\right)}{\partial \tau}=0
$$

and the second order condition $\partial^{2}\left(U_{b}+U_{g}\right) / \partial \tau^{2}<0$ holds if the utility function is strictly concave. (If utility is linear, there are no insurance concerns but redistribution still has positive welfare effects as it relaxes liquidity constraints.) When there are no liquidity constraints, the aggregate ex ante welfare effect of taxation and subsidization is

$$
\begin{aligned}
\frac{d\left(U_{b}+U_{g}\right)}{d \tau}= & u^{\prime}\left(c_{1(b)}\right) \lambda-u^{\prime}\left(c_{1(g)}\right) \\
& +\beta(1-p) u^{\prime}\left(w_{b}-\left(\kappa+\xi w_{b}\right)\right) \lambda-\beta p u^{\prime}\left(w_{g}-\left(\kappa+\xi w_{b}\right)\right) \\
& +\beta p u^{\prime}\left(w_{b}+a\right) \lambda-\beta(1-p) u^{\prime}\left(w_{g}+a\right)
\end{aligned}
$$

where $c_{1(i)}$ denotes consumption in the first period with labor income $w_{i}$.

If $\lambda=1$, then eliminating all laissez faire income differences by setting $\tau=\left(\omega_{g}-\omega_{b}\right) / 2$ equates (13) to zero, and satisfies the first order condition for maximization of the ex ante welfare criterion, as long as the liquidity constraint is not binding for the resulting flat income profile. $^{5}$ In the more realistic case where $\lambda<1$, the tax rate $\tau$ should balance the redistribution policy's insurance benefits and deadweight losses. In a static environment, the ratio of marginal utilities should be set equal to $\lambda$, as would be implied by separately setting to zero each of the three lines of equation (13). In the dynamic environment we are analyzing, however, redistribution that fails to offer perfect insurance (because $\lambda<1$ ) also affects saving behavior. The optimal tax policy would in general call for different tax rates in the two periods but, whether or not this is allowed, the deadweight losses represented by $\lambda<1$ prevent policy from achieving perfect consumption smoothing.

\footnotetext{
${ }^{4}$ The model could determine the incidence of borrowing constraints if initial income included a purely temporary idiosyncratic shock, or if discount rates were heterogeneous. The persistence of labor income shocks would be one of the determinants of the fraction of constrained individuals in such specifications.

${ }^{5}$ Liquidity constraints would bind upon complete cross-sectional redistribution if $\beta(1+r)<1$ : a positive shadow price to the expression (13) would then lead policy to a fully egalitarian corner optimum.
} 
In the realistic case where redistribution generates deadweight losses and liquidity constraints bind for some agents, the policy offers insurance from the ex ante point of view and also decreases the need to borrow, as it smooths income not only across realizations of the model's random variable but also over time for each individual. Totally differentiating the first-order condition $\partial\left(U_{b}+U_{g}\right) / \partial \tau=0$ for any given $\kappa$,

$$
\frac{d \tau}{d \kappa}=-\left[\frac{\partial^{2} U_{b}}{\partial \tau \partial \kappa}+\frac{\partial^{2} U_{g}}{\partial \tau \partial \kappa}\right] / \frac{\partial^{2}\left(U_{b}+U_{g}\right)}{\partial \tau^{2}}
$$

is negative if the conditions of Result 1 hold and $\frac{\partial^{2} U_{b}}{\partial \tau \partial \kappa}<0$, because $\frac{\partial^{2} U_{g}}{\partial \tau \partial \kappa}=0$ and the denominator is negative by the second order condition of the policy-choice problem. This establishes

Result 3: If the initially low-wage workers are liquidity constrained, and condition (10) holds, a larger $\kappa$ implies a smaller optimal redistribution rate $\tau$ for any $\lambda<1$.

In our partial-equilibrium framework with a fixed interest rate, credit constraints only affect the marginal utility gains from redistribution for the currently poor who would like to borrow: their relaxation has no bearing on the welfare of positive-asset individuals, and beneficial effects for other individuals. Thus, the ex ante criterion makes it optimal to choose a more incisive redistribution policy when borrowing is more heavily constrained ( $\kappa$ is small): lack of intertemporal consumption-smoothing opportunities strengthens the standard intratemporal, insurance-based incentives to implement redistribution policies along the lines of Varian (1980) and related studies.

We next explore the interaction between credit constraints, redistribution, and labor income persistence, which may itself be affected by policy and institutions. Adding the expressions in (11) and (12) and rearranging, the impact of $p$ on our baseline ex ante policy-choice criterion is

$$
\begin{aligned}
\frac{\partial\left(U_{b}+U_{g}\right)}{\partial p}= & \beta\left[u\left(w_{g}-\kappa-\xi w_{b}\right)-u\left(w_{g}\right)+u\left(w_{b}\right)\right. \\
& \left.-u\left(w_{b}-\kappa-\xi w_{b}\right)+u\left(w_{b}+a\right)-u\left(w_{b}\right)+u\left(w_{g}\right)-u\left(w_{g}+a\right)\right],
\end{aligned}
$$

which is unambiguously positive, by concavity of the utility function, as long as redistribution is incomplete and $w_{g}>w_{b}$. Our simple model of labor-income dynamics associates high marginal utility with the expectation of income improvement. As pointed out by Flinn (2002), lower persistence of mean-reverting labor income shocks decreases lifetime inequality, with beneficial effects on our inequality-averse ex ante welfare objective. However, this effect depends on the availability of credit: since

$$
\frac{\partial\left(U_{b}+U_{g}\right)}{\partial p \partial\left[\kappa+\xi w_{b}\right]}=\beta\left[u^{\prime}\left(w_{b}-\kappa-\xi w_{b}\right)-u^{\prime}\left(w_{g}-\kappa-\xi w_{b}\right)\right]>0
$$


we can state

Result 4: If $u(\cdot)$ is strictly concave and for any $w_{g}>w_{b}$ resulting from (incomplete) laborincome redistribution, the welfare effects of income instability are less positive when credit is more restricted.

Intuitively, unstable labor incomes are less desirable when binding liquidity constraints on currently low-income workers dilute the welfare benefits of steeper expected labor-income profiles. Access to credit is more desirable when labor income is less smooth. And when credit supply conditions are underdeveloped, labor market volatility is not as ex ante welfareenhancing for risk-averse workers as it would be if financial markets made it possible to align current and expected future marginal utility. ${ }^{6}$

\section{Empirical evidence}

Of course, current and prospective labor incomes are much more heterogeneous across workers in reality than in our model. The simple structure of the model's labor-income levels and transitions implies that relatively poor individuals would like but might not be able to borrow, since their labor income may but need not increase. This specific channel of interaction needs to be isolated in more complex data by appropriately controlling for features we left unmodelled above. It is equally obvious that the model's assumption of a precise limit to the lender's loan-recovery power and of a sharp lower bound for the consumer's future income approximate imperfectly a much more complex reality. But our simple assumptions do capture realistic features of real-life economies where bad luck in the labor market may be more or less extreme and may have more or less drastic consequences on borrower's repayments, depending on the structure of labor and credit markets. Hence, the simple results regarding the role of the parameters indexing the repayment limit offer general qualitative insights that deserve to be confronted with available empirical information.

As we proceed to seek empirical confirmation of results regarding endogenous determination of policy preferences and configurations, we need to formulate precise identification

\footnotetext{
${ }^{6}$ Result 4 offers a clear characterization of labor-income volatility's interaction taking as given the extent of cross-sectional wage inequality, $w_{g}-w_{b}$, and the repayment limit $\kappa+\xi w_{b}$. If the wage structure and unlucky workers' repayment ability are viewed as the endogenous result of redistributive policies motivated by the financial market imperfections indexed by $\kappa$ in the model, a larger $\kappa$ reduces the extent of desirable redistribution for any deadweight loss (as indexed by $\lambda$ ). The cross-derivative welfare effects of $\kappa$ and $p$ remain positive as in Result 4 unless the higher second-period consumption volatility for initially lucky workers more than offsets the other effects in the aggregate welfare expression.
} 
assumptions, because policies and their effects are jointly determined by variation in underlying characteristics across observations (see Besley and Case, 2000, for a general discussion and an illustrative application). While available cross-country information is far from being so precise and plentiful as to support instrumental variable estimation, when interpreting the patterns of covariation apparent in the data we will view countries' historically determined legal traditions or "judicial efficiency" as the exogenous determinant of credit supply conditions and, through the theoretical mechanism identified above, of incentives to smooth labor incomes. From this perspective we first explore the cross-country relationship between citizen's attitudes towards the relevant policies and the availability of consumer credit, and then discuss how actual labor market policies implemented across all the countries for which information is available may be rationalized by our theoretical results.

\subsection{Credit and the taste for redistribution}

Data from the International Social Survey Programme (ISSP) offer an opportunity to assess directly the relationship between credit market development and the perceived benefits of income equality. The simple results of Section 2.1 provide a stylized representation of interactions between the welfare effect of redistribution, credit availability, and personal circumstances. Following the approach of Alesina and La Ferrara (2001), we assess the extent to which those welfare effects are reflected in citizens' attitudes towards government redistribution policies. We construct a 1-to-5 indicator of "taste for redistribution" from the answers to the survey's question regarding support for a government role in reducing income inequality (see the Data Appendix for details).

Before analyzing the microeconomic data, it is interesting to consider country aggregates. Figure 3 displays the average taste of redistribution and consumer credit volume for all available country-year observations points. ${ }^{7}$ Credit volume depends on demand factors as well as on the supply conditions our model views as a source of cross-country variation. To the extent that credit volume reflects supply conditions, citizens feel less of a need for government redistribution when credit supply is restricted according to our Result 1 . And to the extent that the desire for redistribution translates into more intense redistribution and labor market regulation, as suggested by our Results 3 and 4, a lower credit volume is consistent with reduced demand for credit by consumers whose labor income is relatively stable (see the Appendix for further discussion of such demand-side effects). In the Figure, a broadly negative relationship is

\footnotetext{
${ }^{7}$ Data on consumer credit are available for 8 countries covered by the ISSP and only 4 of these countries are covered by all 3 waves of the ISSP with questions on redistribution. Data on consumer credit are averages of the volume of consumer credit for a five-year window around the respective dates.
} 


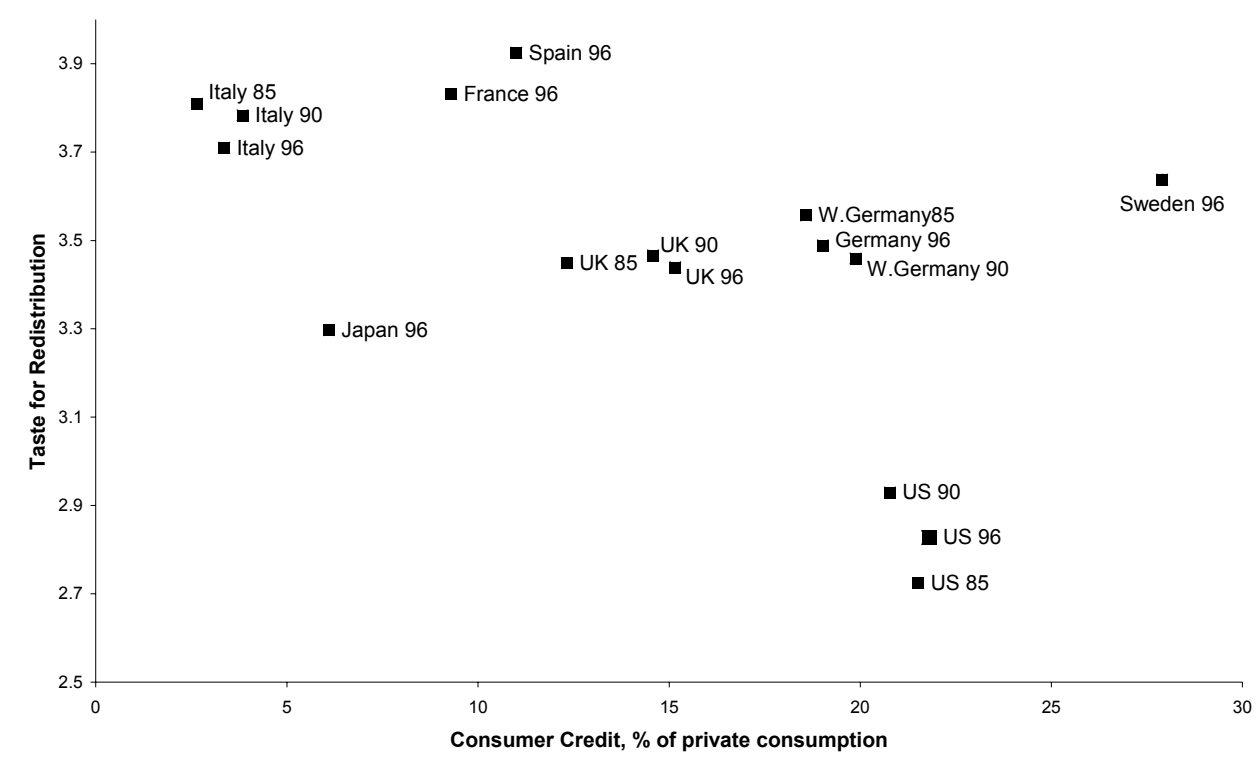

Figure 3: Cross- and within-country relationship between the volume of consumer credit and average survey attitutes towards government redistribution; Source: see the Data Appendix.

consistent with this theoretical perspective. Time-series movements of consumer credit and policy preferences also appear to follow the predicted downward-sloping relationship for the few countries for which data are available. ${ }^{8}$

The variation in the data is clearly much stronger across countries than over time, however. Cross-country data on credit supply indicators (loan-to-value ratios and judicial efficiency) are available for 15 of the countries covered by the ISSP in 1996 (see the Data Appendix). The simple correlation between the country-specific average survey answers is -0.25 with the LTV ratio, and -0.20 with the judicial efficiency indicator: hence, on average the citizens of countries where credit access is limited and judicial enforcement is poor do tend to support government redistribution more.

To test for the effects identified by our theoretical model, we run ordered probit regressions on specifications including the many individual characteristics for which data are available for country-year observations. Empirically, we assess the relationship between country-specific characteristics regarding access to credit, individual-specific characteristics relevant not only to

\footnotetext{
${ }^{8}$ These may reflect within-country institutional changes. See ECRI (2000) for a discussion of legislative innovations in some of the countries considered, in particular those related to European Commission Consumer Credit Directives in 1986, 1990, and 1998.
} 
benefits from redistribution but also the desire to borrow, and the same individual's attitudes towards government redistribution. It will not be surprising to find that poor individuals favor redistribution more than rich individuals. On the basis of the assumptions made above and of the theoretical results of Section 2.1, however, we expect the strength of feelings in favor of redistribution to be affected by credit availability, and particularly so in the case of individuals whose desire to borrow and smooth consumption is stronger.

Table 1 displays the results of ordered probit specifications that index credit availability with the loan to value (LTV) variable. Using judicial efficiency yields broadly similar, if somewhat less supportive results. To disentangle inter- and intratemporal gains from redistribution, we need to focus on the interaction of individual inclination to borrow with country-specific credit-supply indicators. The coefficients of interest are those of interactions of LTV indicators with income quartiles, meant to capture the effect of credit market development on the currently poor individuals' support for redistribution, and with interactions of income quartiles with age, meant to capture differences in the prospects of upward mobility and desire to borrow. We also include a host of other control variables. ${ }^{9}$ Their coefficients (not shown) are allowed to vary across countries in the specification reported in the second column, which also includes country-specific intercepts. Significance levels are corrected for error-clustering across individual observations from the same countries.

The log likelihood statistics indicate that the data strongly reject equality of coefficients across countries. The estimates of the coefficients of interest, however, are quite similar in the two columns, and the pattern of their signs and significance levels offers support to our theoretical results.

After controlling for individual characteristics and interactions, the country-specific coefficient of the LTV variable is completely insignificant. Hence, the average statistics displayed in Figure 3 reflect heterogeneous support for redistribution in countries with different credit conditions. The character of heterogeneous support is captured by the interaction terms. Within each country, agents with lower income are not surprisingly in favor of more redistribution, and relatively more so if they are younger (the coefficients are positive and significant at the $5 \%$ level for the first and second income quartile; negative and significant for the interactions with age). But the coefficients of the boldface interaction variables in Table 1 indicate that both effects are significantly smaller in countries with more developed credit markets.

\footnotetext{
${ }^{9}$ We include essentially all covariates available for the countries where we have information relevant to our results. Union membership indicators, which may be endogenously related to individual preferences for redistribution, are excluded from the regressions we report but have no qualitative impact on the results. Experimentation with different covariate sets, such as occupation or self-reported social status as controls for income permanence, were inconclusive but did not offer evidence against our theoretical proposition.
} 


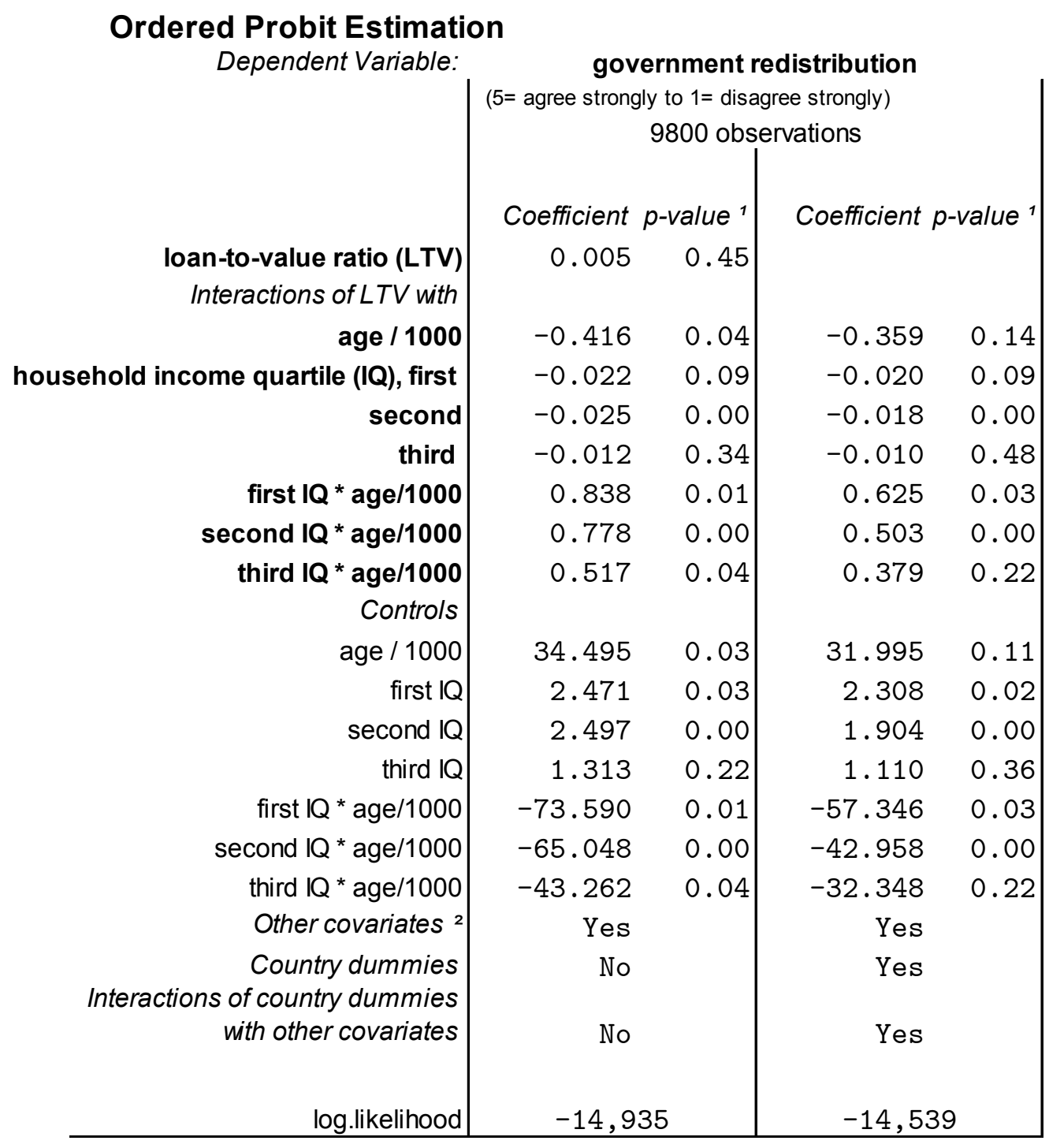

${ }^{1} \mathrm{p}$-values are computed on the basis of standard errors robust to country-level covariance clustering.

2 The specifications also include: sex, married, married*spouse unemployed, currently unemployed, completed secondary school, completed university degree, retired, disabled, self employed, middle class, upper class.

Sources: Micro data from ISSP 1996; merged with available country-specific loan-tovalue ratios ratio from Jappelli and Pagano (1994). Spain and Israel excluded because of missing covariates.

Table 1: Ordered probit results. 
Finding that poor agents are more in favor of redistribution in countries where credit supply conditions are more restrictive is consistent with Result 1. And the interaction of credit supply conditions with the age effect is consistent with Result 2. Like the agents with low first-period income in the model of Section 2, younger agents expect higher future incomes but, since that expectation need not be realized, cannot access credit easily. As predicted by theory, the interaction between citizens' taste for redistribution and credit supply conditions is empirically stronger among individuals with stronger prospects of upward income mobility and, therefore, stronger desire to borrow. (Both the intratemporal motive for redistribution and the intertemporal motive are quantitatively important: LTV is measured in percent terms, so the small coefficients of the interactions with the loan-to-value ratio are applied to data ranging from 30 to 95 )

We have also run ordered probit regressions with no cross-country restrictions on all the slope coefficients, and tested whether country-specific coefficients of age, income, and ageincome interactions are linear functions of LTV indicators, as in the second column of Table 1. Of course, many other country-specific factors influence these coefficients: a likelihood ratio test rejects that simple specification at a $p$-value of about $0.5 \%$. But the sizable robust $t$-statistics reported in Table 1 do indicate that LTV plays an important role in shaping the relationship between different individuals' economic circumstances and policy preferences.

In summary, data on the different taste for redistribution of citizens in different economic conditions offer considerable support to the theoretical mechanism proposed in Section 2.1 above. More developed credit markets indeed seem to lower the desire for redistribution of currently poor agents, by offering channels of consumption smoothing and strengthening the welfare impact of upward mobility prospects. The effect is particularly strong, and more directly supportive of our theory, among young individuals who-like the initially low-income agents of the model - are more likely (but far from sure) to experience upward mobility than the rest of the population.

\subsection{Credit and labor market institutions across countries}

The theoretical and empirical effects considered in the previous subsection are independent of whether or not redistribution policies advocated by individuals are implemented in their own country. But the strength of support for government redistribution should of course bear on actual policy implementation, on the basis of the ex ante welfare criterion considered above or of more complex politico-economic interactions. Accordingly, we proceed to assess whether and to what extent the influence of credit conditions on citizens' attitudes towards redistribution is reflected in their countries' actual institutional configuration, bearing in mind that the 
relationship between theoretical insights and empirical evidence can of course be confounded by cross-country heterogeneity of policymaking frameworks.

A variety of policies do limit the extent of labor-income variability at the cost of efficiency losses in reality. The simplest real-life counterpart to the formal analysis above is perhaps progressive taxation or unemployment insurance schemes. Such policies reduce uncertainty about each worker's disposable income at the same time as they decrease individual incentives to exert on-the-job or search effort, an effect represented by our model's "leaky bucket" parameter $\lambda$. Redistribution across lucky and unlucky workers, however, need not take the form of explicit tax and subsidy policies, and policy interventions' efficiency costs can be due to labor misallocation at the aggregate level as well as to low effort at the individual level. Wage compression in mandatorily extended collective contracts can smooth pre-tax labor income (Agell and Lommerud, 1992), and employers can provide some income-smoothing services to workers even in the absence of formal contracts (Guiso et al., 2002, find that in Italy wages only reflect permanent, rather than transitory, firm-specific shocks). Further, employment protection legislation has similar implications, as they try to protect uninsured workers from "unfair" consumption fluctuations but, due to the same informational imperfections that prevent markets from delivering appropriate insurance, cannot do so without burdening employers and employees with judicial and administrative costs (Bertola, 2004). EPL and other labor market institutions can also affect persistence of labor-market outcomes, which differs importantly across countries as well as across occupations within a country. A formal model of this mechanism, and of the relationship between the wage-compressing and labor turnover implications of EPL, is beyond the scope of this paper. But since unemployed workers' job-finding probabilities are empirically lower when EPL is stringent (see, e.g., Bertola and Rogerson, 1997), high persistence of both employment and unemployment labor-market states should reduce all workers' desired borrowing. If unemployment is concentrated on younger labor market entrants, however, then the same employment protection that alleviate borrowing constraints for mature employed workers also makes them more binding for young, unemployed workers who would like to borrow for life-cycle reasons and, as in Fogli (2000), may need to rely on parental resources instead.

Observable empirical policy and outcome indicators are available as regards the extent of $e x$ post labor income inequality across OECD economies. As shown by the correlations reported in Table 2, stringent employment protection legislation tends to be associated with lower labor income risk, in the form of longer job tenures, smaller wage differentials in the lower portion of the overall wage distribution, and more persistence in realized wages. To the extent that industrialized countries' labor markets are technologically similar, their citizens' different labor 


\begin{tabular}{|c|c|c|c|c|c|c|}
\hline & $\begin{array}{l}\text { Overall } \\
\text { EPL in } \\
\text { the late } \\
1990 \mathrm{~s}\end{array}$ & $\begin{array}{c}\text { Mean } \\
\text { tenure, all } \\
\text { jobs, } \\
1995\end{array}$ & $\begin{array}{c}\text { 1990s } \\
\text { earnings } \\
d 5 / d 1\end{array}$ & $\begin{array}{c}\text { Overall } \\
E P L \\
\text { rank, } \\
1989\end{array}$ & $\begin{array}{c}\text { Mean } \\
\text { tenure, all } \\
\text { jobs, circa } \\
1985\end{array}$ & $\begin{array}{c}1980 s \\
\text { earnings } \\
d 5 / d 1\end{array}$ \\
\hline \multirow{6}{*}{$\begin{array}{l}\text { Mean tenure, all jobs, } 1995 \\
1990 \text { s earnings d5/d1 } \\
\text { Overall EPL rank, } 1989 \\
\text { Mean tenure, all jobs, circa } 1985 \\
1980 \text { s earnings d5/d1 } \\
\text { Earnings correlation 1986-91 }\end{array}$} & 0.77 & & & & & \\
\hline & -0.52 & \begin{tabular}{|c|}
-0.65 \\
\end{tabular} & & & & \\
\hline & 0.95 & 0.86 & -0.64 & & & \\
\hline & 0.83 & 0.72 & -0.16 & 0.75 & & \\
\hline & -0.41 & -0.43 & 0.96 & -0.49 & -0.34 & \\
\hline & 0.77 & 0.77 & -0.65 & 0.88 & 0.93 & -0.10 \\
\hline
\end{tabular}

Table 2: Correlation of employment protection indicators with wage inequality (median to first decile ratio, all jobs), mean complete tenure (all jobs), and earnings instability (Pearson's Rho) indicators.

income security largely reflects institutional differences. The stability over time of labor income institutions suggests that the ex ante policy perspective of Section 2.2 may be qualitatively relevant to observed policy outcomes. That perspective, like any policy-choice framework giving positive weight to the preferences of borrowers, suggests that the same economies that find it difficult to provide consumption-smoothing services in the financial market should also find it attractive to implement (inefficient) government redistribution policies: when borrowing and other forms of financial market access are difficult, only smooth incomes may support smooth consumption profiles.

In order to assess the empirical relevance of our theoretical perspective for such policies as are actually implemented, we report in Table 3 rank correlation statistics across a variety of indicators, defined in the Data Appendix and discussed below in light of our theoretical results. The $p$-values are reported below the correlation coefficients, and correlations significant at the $5 \%$ level are marked with a star. Since there are at most 23 observations, it is not surprising that only about half of the correlations are significant: the evidence can at best be suggestive. Timevarying data on credit and financial institutions could of course provide a better assessment of the relevant mechanisms' empirical relevance, but data on household credit are available for most countries only for the 1990s. Financial and labor market regulation indicators are based on 1980s evidence. The correlations we focus on, however, are not likely to be affected by such imperfect synchronicity of the indicators. While both credit and labor market conditions have certainly varied over time, the relative position of countries is quite stable: as shown in Table 2, labor market outcomes and institutions are highly stable over time, and the relationships we illustrate are very similar when 1980s credit volume measures (available for a subset of 


\begin{tabular}{|c|c|c|c|c|c|c|c|c|c|c|}
\hline & $\begin{array}{c}\qquad \text { Incc } \\
\text { Emplo. } \\
\text { Prot. } \\
\text { Legisl. }\end{array}$ & $\begin{array}{c}\text { Wage inequa } \\
\text { Differenti } \\
\text { al D5/D1 }\end{array}$ & $\begin{array}{l}\text { ty: } \\
\text { H.hold } \\
\text { net } \\
\text { income } \\
\text { D9/D1 }\end{array}$ & $\begin{array}{l}\text { Pearson's } \\
\text { Rho }\end{array}$ & $\begin{array}{l}\text { Spearm. } \\
\text { rank corr. }\end{array}$ & $\begin{array}{l}\text { lity: } \\
\text { Average } \\
\text { Quintile } \\
\text { Move }\end{array}$ & $L T V$ & $\begin{array}{l}\text { Judicial } \\
\text { Effic. }\end{array}$ & $\begin{array}{l}\text { Total } \\
\text { Credit }\end{array}$ & $\begin{array}{c}\text { Consum } \\
\text { Credit }\end{array}$ \\
\hline \multirow{2}{*}{$\begin{array}{r}\text { Wage Differential } \\
D 5 / D 1\end{array}$} & $-0.6402^{*}$ & & & & & & & & & \\
\hline & 0.0076 & & & & & & & & & \\
\hline \multirow{2}{*}{$\begin{array}{l}\text { Household income } \\
\text { D9/D1, after tax }\end{array}$} & $-0.5469^{*}$ & $0.7676^{*}$ & & & & & & & & \\
\hline & 0.0349 & 0.0005 & & & & & & & & \\
\hline \multirow[t]{2}{*}{ Pearson's Rho } & $0.8571^{*}$ & -0.4857 & -0.1429 & & & & & & & \\
\hline & 0.0137 & 0.3287 & 0.7599 & & & & & & & \\
\hline \multirow{2}{*}{$\begin{array}{r}\text { Spearman Rank } \\
\text { correlation }\end{array}$} & 0.7027 & -0.2319 & 0.1081 & $0.9009^{*}$ & & & & & & \\
\hline & 0.0782 & 0.6584 & 0.8175 & 0.0056 & & & & & & \\
\hline \multirow{3}{*}{$\begin{array}{r}\text { Average Quintile } \\
\text { Move }\end{array}$} & & & & & & & & & & \\
\hline & -0.6429 & 0.5429 & 0.1429 & $-0.8214^{*}$ & $-0.8829^{*}$ & & & & & \\
\hline & 0.1194 & 0.2657 & 0.7599 & 0.0234 & 0.0085 & & & & & \\
\hline \multirow{2}{*}{$\begin{array}{r}\text { Loan-toValue } \\
\text { ratio }\end{array}$} & $-0.5694^{*}$ & 0.1163 & 0.0847 & $-0.7819^{*}$ & $-0.8257^{*}$ & 0.5274 & & & & \\
\hline & 0.0137 & 0.6354 & 0.7552 & 0.0378 & 0.0221 & 0.2238 & & & & \\
\hline \multirow[t]{2}{*}{ Judicial Efficiency } & $-0.681^{*}$ & -0.1857 & -0.1819 & $-0.7881^{*}$ & $-0.7754^{*}$ & 0.6108 & $0.6259^{*}$ & & & \\
\hline & 0.0020 & 0.4332 & 0.4847 & 0.0353 & 0.0405 & 0.1451 & 0.0014 & & & \\
\hline \multirow[t]{2}{*}{ Total Credit } & $-0.8064^{*}$ & 0.3182 & 0.2727 & -0.7714 & -0.6377 & 0.6000 & $0.8325^{*}$ & $0.6457^{*}$ & & \\
\hline & 0.0027 & 0.3403 & 0.4458 & 0.0724 & 0.1731 & 0.2080 & 0.0008 & 0.0233 & & \\
\hline \multirow{2}{*}{ Consumer Credit } & -04146 & 02000 & ก $200 \Omega$ & 04286 & 06088 & 02000 & 0 8854* & 02086 & $07483^{*}$ & \\
\hline & $\frac{-0.4140}{0.2049}$ & 0.5554 & 0.5796 & $\frac{-0.4 \angle 00}{0.3965}$ & $\begin{array}{l}-0.0000 \\
0.1997\end{array}$ & 0.7040 & 0.0001 & 0.2900 & 0.0051 & \\
\hline \multirow[t]{2}{*}{ Mortgage Credit } & $-0.7973^{*}$ & 0.3545 & 0.2485 & -0.7714 & -0.6377 & 0.6000 & $0.7337^{*}$ & $0.6457^{*}$ & $0.9790^{*}$ & $0.6294^{*}$ \\
\hline & 0.0033 & 0.2847 & 0.4888 & 0.0724 & 0.1731 & 0.2080 & 0.0066 & 0.0233 & 0.0000 & 0.0283 \\
\hline
\end{tabular}

Table 3: Spearman rank-correlations across policy and outcome indicators (see the Appendix for definitions and sources). Sample sizes used to calculate the correlations vary depending on data availability. P-values are reported below the correlation coefficients. Coefficients that are significant at the 5 percent level are marked with a star; Source: see the Data Appendix.

countries) are used instead of the more recent ones.

The relationship between the judicial efficiency indicator and credit supply conditions, summarized by the loan to value ratio (LTV), is positive and significant in our Table 3, as in La Porta et al. (1998) and other recent contributions. ${ }^{10}$ Other bivariate correlation evidence broadly supports the sign predictions of our model and empirical perspective. Table 3 reports rank correlations for two income-inequality indicators: the ratio of the 50th to the 10th percentile of the gross earnings distribution, and the differential between the 90th and 10th decile of the household disposable income distribution. Neither indicator is perfectly suited to

\footnotetext{
${ }^{10}$ Claessens and Klapper (2003, Table 5) report strongly significant coefficients for "Rule of Law" in their regressions for various creditor rights indicators in the case of firms' financial distress. We are not aware of similar evidence for consumer credit.
} 
our purposes, since the former disregards tax-and-subsidy-based redistribution, and the latter includes capital income. The two are highly correlated, however (across countries, tax-based redistribution is more intense where gross earnings are more compressed by contractual and other provisions) and both are positively (if insignificantly) related to LTV. ${ }^{11}$ This is consistent with Result 3, since high LTV, indexed by $\kappa$ in the model, should be associated with more unequal incomes inasmuch as labor market outcomes are less compressed by policies and institutions. Labor income inequality is however negatively (and again insignificantly) related to the more indirect judicial-efficiency indicator of credit availability.

Indicators of earnings (in)stability, which are correlated with the EPL indicators, are the empirical counterpart of our theoretical parameter $p$ and also offer some support to our theoretical insights. Result 4 suggests that volatile labor incomes are more attractive in countries where easy credit access makes it possible to smooth out their implications for consumption patterns; empirically, countries where earnings are more unstable (as indicated by high values of Average Quintile Move statistics, and low values of the earnings autocorrelation statistics) are also those with high LTV and judicial efficiency indicators. All the rank correlations between these variables have the predicted sign in Table 3, and are strongly significant as regards earnings autocorrelations. In summary, evidence of a positive relationship between credit supply conditions and income inequality and volatility indicators supports the idea that an efficient financial market makes labor income instability more socially appealing.

We also report correlations between labor or credit market features on the one hand, and credit volume on the other. Our theoretical perspective does not offer unambiguous predictions regarding relationships between credit supply, labor market configurations, and credit volumes. In reality, not all borrowers are liquidity constrained (as we assumed in deriving our simple theoretical results). Hence, credit volume reflects demand factors as well as supply conditions. In general, demand for credit depends on many structural factors that may well differ across economies, and supply conditions may respond endogenously to such factors if economies of scale reduce the cost and further increase the volume of credit in countries where demand for credit is strong. In the Appendix we show formally that in our simplified model credit demand increases with earnings instability - see equation (A1) - and increases with wage differentials if marginal utility is not too convex - see equations (A2) and (A3). By Assumption 1, however, credit supply decreases when wage differentials are larger, in particular as a smaller $w_{b}$ reduces repayment capacity.

\footnotetext{
${ }^{11}$ The correlation becomes much stronger if the sample excludes Korea, and stronger still if Finland, Norway, and Sweden are excluded as well. Controlling for observable and unobservable characteristics of these and other countries could yield cleaner and more informative empirical relationships. In practice, lack of information prevents formal estimation.
} 
Our Result 3 predicts that worse credit conditions should lead to more extensive redistribution policies. Since labor market regulation entails deadweight losses, it is an imperfect substitute for a better judicial system, and should only partly offset the direct credit-supply effect of poor enforcement: empirically, the correlation between credit volume and judicial system efficiency is indeed positive. The statistics reported in Table 3 offer other, albeit limited insight as to the empirical prevalence of different interaction channels. The bivariate correlations between judicial efficiency, LTV, and credit volumes are positive, indicating that supply conditions are important for aggregate borrowing (as emphasized by Jappelli and Pagano, 1994); but the correlation between credit volume measures and measures of income inequality and volatility is positive as well, indicating that demand effects also matter. Of course, bivariate correlations provide a very limited basis for statistical inference. Ideally, we would like to assess the extent to which credit volume is (through demand effects) related to the characteristics of labor income processes after conditioning on supply features (as indexed by the LTV ratio). In practice, the amount and character of available cross-country information is far from being amenable to formal econometric modelling.

\section{Concluding remarks}

Needless to say, additional work could flesh out our model's implications in more complex and realistic terms. The mechanisms through which redistribution or labor-income compression entail deadweight costs could be modelled explicitly, and need not be independent of the circumstances determining credit access: for example, if better developed financial markets make it easier for agents to elude taxation, then the efficiency costs of redistribution would be larger in the same economies that value its consumption-smoothing role less, strengthening the correlation implied by Result 3. Similarly, the particularly sharp limitation of credit access in our Assumption 1 could be relaxed to treat explicitly more sophisticated forms of financial market imperfections. It would then be possible to study the extent to which consumer credit bureaus (in turn influenced by privacy and competition concerns) may improve credit opportunities, and to characterize how bankruptcy rules may make credit more difficult to obtain while at the same time offering some insurance against persistently bad labor market outcomes. This is yet another reason why economies with sophisticated credit markets, like the United States, may find a deregulated labor market appealing.

The complex phenomena and evidence we study can be approached from many other theoretical perspectives. In general, the costs and the benefits of many other institutional features interact importantly in reality, within as well as across markets. Within the labor market, wage 
rigidity increases the impact of EPL on employment and labor mobility patterns (Bertola and Rogerson, 1997), and other policies are substitutable to each other: unemployment benefits and EPL, for example, aim at similar objectives through different means, and the relative merits of each depend on details of their implementation and of the economy's structure (Bertola, 2004). Across markets, labor market institutions may partially compensate for inefficient financial contract enforcement, and the structural and policy implications of financial market conditions may be wider still. For example, the empirical evidence studied by Fogli (2000) shows that in countries with stringent EPL, unemployment is particularly concentrated among young people who live with their parents. Since within-family transfers can perform some of the functions of formal financial markets, the structure of labor and credit markets can indeed influence family structure if the latter is endogenous.

Redistribution and labor market regulation, however, do appear theoretically and empirically more desirable when credit supply constraints are more binding. Viewing judicial efficiency as an exogenous determinant of credit supply conditions, we have shown that countries with poor judicial efficiency and tight credit report more pronounced appreciation for government redistribution in survey answers, especially by likely borrowers, and also tend to feature more labor market regulation and more equal, less volatile labor-income. Policymakers should of course aim at loosening liquidity constraints. But if it is difficult, slow, and expensive to reform judicial and legal traditions determined by historical circumstances, then our theoretical perspective and empirical result suggest that structural and reform issues should be discussed in a broader context than is usually the case. Since increasing income insecurity makes it all the more painful for workers to lack access to consumption smoothing instruments, labor market deregulation does not improve the economy's ability to deliver welfare to its citizens unless accompanied by reforms aimed at easing borrowing constraints. Historical legacies help our and related empirical work to identify the empirical effects but do not condemn countries to perpetually different systems of economic relations (see Rodrik et al., 2002). Thus, labor market institutions should be updated when an economy's credit markets develop: from this perspective, it is not surprising to witness heavy resistance to labor market liberalization in countries in which credit supply remains relatively constrained, such as Italy, while the United Kingdom's high level of financial market development may well have allowed that country to drastically reform its labor market in the 1980s (Koeniger, 2004). 


\section{Appendix}

Our simple results focus on constrained borrowing, so that only supply conditions determine the volume of credit. Agents borrow more when $\kappa$ is larger, and redistribution affects borrowing as it relaxes supply conditions through the repayment-ability effect indexed by $\xi$. Stability of labor income also reduces the initially unlucky workers' desire to borrow, and in reality the observed volume of credit is in general the result of institutional influences on both demand and supply.

When bringing our simple model's insights to bear on a more complex reality where some borrowing is performed by unconstrained agents, we need to characterize the amount borrowed when the Euler equation

$$
u^{\prime}\left(w_{b}-\frac{b}{1+r}\right)=\beta(1+r)\left[p u^{\prime}\left(w_{g}+b\right)+(1-p) u^{\prime}\left(w_{b}+b\right)\right]
$$

is satisfied. Totally differentiating,

$$
\frac{d b}{d p}=\beta(1+r)\left[\frac{u^{\prime}\left(w_{g}+b\right)-u^{\prime}\left(w_{b}+b\right)}{-u^{\prime \prime}\left(w_{b}-\frac{b}{1+r}\right) \frac{1}{1+r}-\beta(1+r)\left[p u^{\prime \prime}\left(w_{g}+b\right)+(1-p) u^{\prime \prime}\left(w_{b}+b\right)\right]}\right]<0 .
$$

The inequality follows because the numerator is negative as long as $w_{g}>w_{b}$ and the denominator is positive for strictly concave utility. Since $b<0$, this means that less persistence (a larger $p$ ) implies more borrowing. This is quite intuitive because average lifetime income is relatively higher than current resources when the labor income is more unstable and agents have received a bad draw in the first period. Symmetrically, the unconstrained desired lending of currently lucky individuals is larger when $p$ is larger.

For given persistence, similar derivations establish that wider fluctuations in wages imply more credit demand:

$$
\frac{d b}{d w_{g}}=\beta(1+r)\left[\frac{p u^{\prime \prime}\left(w_{g}+b\right)}{-u^{\prime \prime}\left(w_{b}-\frac{b}{1+r}\right) \frac{1}{1+r}-\beta(1+r)\left[p u^{\prime \prime}\left(w_{g}+b\right)+(1-p) u^{\prime \prime}\left(w_{b}+b\right)\right]}\right]<0 .
$$

and

$$
\frac{d b}{d w_{b}}=\beta(1+r)\left[\frac{(1-p) u^{\prime \prime}\left(w_{b}+b\right)-u^{\prime \prime}\left(w_{b}-\frac{b}{1+r}\right)}{-u^{\prime \prime}\left(w_{b}-\frac{b}{1+r}\right) \frac{1}{1+r}-\beta(1+r)\left[p u^{\prime \prime}\left(w_{g}+b\right)+(1-p) u^{\prime \prime}\left(w_{b}+b\right)\right]}\right]>0,
$$

where the last inequality follows if marginal utility is not so convex as to violate the condition

$$
\frac{u^{\prime \prime}\left(w_{b}-\frac{b}{1+r}\right)}{u^{\prime \prime}\left(w_{b}+b\right)}>1-p .
$$

Higher wages in the bad state of the world imply less borrowing when they are realized in the first period, because the agents who borrow have higher first-period income. But they imply higher borrowing if realized in the second period, since higher expected income leads agents to desire more borrowing. Whether the first or the second effect dominates depends on $p$ and, noting that $w_{b}+b<w_{b}-b /(1+r)$, on the sign of $u^{\prime \prime \prime}(\cdot)$. If labor markets are more turbulent (a larger $p$ ), it is easier for a larger $w_{b}$ to decrease borrowing, because agents who receive a bad draw in the first period are less likely to earn low wages also in the second period. 


\section{Data definition and sources}

Employment protection legislation indicator (EPL) This indicator summarizes legislation for fixed-term and regular employment contracts and is reported for the late 1990s in OECD (1999), Table 2.5, last column. The indicator for 1989 is not explicitly listed in the Tables, but it was possible to obtain it from the OECD. It is very similar to the rank indicators reported in Table 2.6. For 1989 data are available for Australia, Austria, Belgium, Canada, Denmark, France, Finland, Germany, Ireland, Italy, Netherlands, New Zealand, Portugal, Spain, Sweden, UK, US. The EPL indicator for the late 1990s is available for all these countries and Japan, Korea, Norway, Switzerland and Turkey.

Wage differentials We use data on gross-wage differentials between the 50th and 10th decile of the distribution for the 1980s and 1990s. The data can be found in OECD (1996), Table 3.1. Data are available for Australia, Austria, Belgium, Canada, Denmark, France, Finland, Germany, Italy, Japan, Korea, Netherlands, New Zealand, Portugal, Sweden, UK, US.

Household income inequality We use data on differentials of household disposable income per equivalent adult between the 90th and 10th decile of the distribution as reported in Gottschalk and Smeeding (1997), Figure 2, column 3. The data are from the 1980s or early 1990s depending on the country and are available for Australia, Austria, Belgium, Canada, Denmark, France, Finland, Germany, Ireland, Italy, Netherlands, Norway, Spain, Sweden, Switzerland, UK, US.

Earnings instability We use three alternative measures of earnings instability: Pearson's rho, the Spearman rank correlation and the average quintile move. Note that the first two measures are larger if income is more stable whereas the opposite holds for the third measure. The data are from OECD (1996), Table 3.5, and are available over the 1986-91 period for Denmark, France, Germany, Italy, Sweden, UK, US.

Mean tenure The data on mean tenure for all jobs in 1985 and 1995 are reported in OECD (1997), Table 5.7, column 4 and Table 5.5, column 9, respectively. Data for 1985 are available for Australia, Canada, France, Finland, Germany, Greece, Japan, Netherlands, Spain, UK, US. The data for 1995 are available for the same countries plus Austria, Belgium, Denmark, Ireland, Italy, Korea, Portugal, Sweden, Switzerland.

Loan-to-value (LTV) ratio The loan-to-value ratio measures the maximum fraction of house value financed by collateralized mortgages in 1981-87. It is reported in Jappelli and Pagano (1994), Table 1, column 3. Data are available for Australia, Austria, Belgium, Canada, Denmark, France, Finland, Germany, Greece, Ireland, Italy, Japan, Korea, Mexico, Netherlands, New Zealand, Norway, Portugal, Spain, Sweden, Turkey, UK, US. For the analysis with the ISSP we add data for Israel and the Philippines from Table 1, column 2 for the time period $1971-80$

Judicial efficiency This variable is a summary indicator for the efficiency of the judicial system which measures the quality of law enforcement. It is constructed for the early 1990s and reported in La Porta et al. (1998), Table 5, column 1. Data are available for a total of 49 
countries among which for the same developed countries as for the LTV ratio plus Switzerland as well as for Israel and the Philippines.

Credit volumes The data for mortgage and consumer credit cover the time period 1990-97 and are constructed by the European Credit Research Institute, ECRI (2000), Table A.8. Data are available for Belgium, Finland, France, Germany, Greece, Italy, Japan, Netherlands, Spain, Sweden, UK, US. The data for Finland are averages for 1993-97.

ISSP data The International Social Survey Programme (ISSP) has collected representative data on the role of the government in the years 1985, 1990 and 1996. The questions of the ISSP are issued as a supplement to existing national surveys. The survey has been used extensively by the international research community (see http://www.issp.org/biblio.htm). In 1985 six countries participated in the survey, comparable data for 1990 and 1985 are available for five countries, and 23 countries participated in the survey in 1996. Since the loan-to-value ratio and judicial efficiency only vary across countries and we do not have information on these variables over time, we use the ISSP 1996 to maximize the number of countries in our cross-sectional regression. Data on the loan-to-value ratio or judicial efficiency is available for 15 of these countries: Australia, Canada, France, Germany, Great Britain, Ireland, Israel, Italy, Japan, New Zealand, Norway, the Philippines, Spain, Sweden and the United States.

We use answers to the following question in the ISSP to measure taste for redistribution:

What is your opinion on the following statement: "It is the responsibility of the government to reduce the differences in income between people with high incomes and those with low incomes."

We code the possible answers as follows: Agree strongly=5, Agree $=4$, Neither agree nor disagree $=3$, Disagree $=4$, Disagree strongly $=1$. Thus, the variable takes larger values if individuals like redistribution more. 


\section{References}

Acemoglu, Daron and Robert Shimer (1999): "Efficient Unemployment Insurance," Journal of Political Economy, vol. 107, 893-928.

Agell, Jonas (2002): "On the Determinants of Labour Market Institutions: Rent Seeking vs. Social Insurance," German Economic Review, vol. 3, 107-35.

Agell, Jonas, and Kjell E. Lommerud (1992): "Union Egalitarianism As Income Insurance," Economica, vol. 59, 295-310.

Alesina, Alberto, and Eliana La Ferrara (2001): "Preferences for Redistribution in the Land of Opportunities," NBER Working Paper No. 8267.

Bénabou, Roland and Efe A. Ok (2001): "Social Mobility and the Demand for Redistribution," Quarterly Journal of Economics, vol. 116, 447-87.

Bertola, Giuseppe (2004): "A Pure Theory of Job Security and Labor Income Risk," Review of Economic Studies, vol. 71, 43-61.

Bertola, Giuseppe and Richard Rogerson (1997): "Institutions and Labor Reallocation," European Economic Review, vol. 41, 1147-71.

Besley, Timothy, and Anne Case (2000): "Unnatural Experiments? Estimating the incidence of endogenous policies," Economic Journal, vol. 110, F672-F694.

Botero, Juan, Simeon Djankov, Rafael La Porta, Florencio Lopez-de-Silanes and Andrei Shleifer (2003): "The Regulation of Labor," NBER Working Paper No. 9756.

Carroll, Christopher (1997): "Buffer-Stock Saving and the Life Cycle/Permanent Income Hypothesis," Quarterly Journal of Economics, vol. 112, 1-55.

Chatterjee, Satyajit, Dean Corbae, Makoto Nakajima and José-Víctor Ríos-Rull (2002): “A Quantitative Theory of Unsecured Consumer Credit with Risk of Default," University of Pennsylvania, mimeo.

Claessens, Stijn and Leora F. Klapper (2003): "Bankruptcy around the World: Explanations of its Relative Use," World Bank, mimeo.

ECRI (2000): "Consumer Credit in the European Union," ECRI Research Report No. 1, Brussels.

Flinn, Christopher (2002): "Labour Market Structure and Inequality: a Comparison of Italy and the U.S.," Review of Economic Studies, vol. 69, 611-45.

Fogli, Alessandra (2000): "Endogenous Labor Market Rigidities and Family Ties," New York University, mimeo.

Gottschalk, Peter and Timothy M. Smeeding (1997): "Cross-National Comparisons of Earnings and Income Inequality," Journal of Economic Literature, vol. 35, 633-87.

Guiso, Luigi, Luigi Pistaferri and Fabiano Schivardi (2002): "Insurance within the Firm," Stanford University, mimeo. 
Jappelli, Tullio and Marco Pagano (1994): "Saving, Growth, and Liquidity Constraints," Quarterly Journal of Economics, vol. 109, 83-109.

Koeniger, Winfried (2004): "Labor Income Risk and Car Insurance in the UK," Geneva Papers of Risk and Insurance Theory, forthcoming.

La Porta, Rafael, Florencio Lopez-de-Silanes, Andrei Shleifer and Robert W. Vishny (1998): "Law and Finance," Journal of Political Economy, vol. 106, 1113-55.

OECD (1996): Employment Outlook, chapter 3, Paris.

OECD (1997): Employment Outlook, chapter 5, Paris.

OECD (1999): Employment Outlook, chapter 2, Paris.

Pagano, Marco and Paolo Volpin (2002): "Workers, Managers, and Corporate Control," CEPR Discussion Paper No. 3649.

Rodrik, Dani, Arvind Subramanian and Francesco Trebbi (2002): "Institutions Rule: the Primacy of Institutions over Geography and Integration in Economic Development," Harvard University, mimeo.

Varian, Hal R. (1980): "Redistributive Taxation as Social Insurance," Journal of Public Economics, vol. 14, 49-68. 